\title{
As três dimensões da cor na reintegração cromática diferenciada: a importância da luminosidade
}

\author{
Ana Braamcamp de Figueiredo y Salomé de Carvalho
}

\begin{abstract}
Resumo: A reintegração cromática diferenciada tem por objetivo a redução da perceção da lacuna como figura, e sobre este princípio basilar pretendemos, mediante os fenómenos de perceção, analisar as três dimensões da cor (tonalidade, saturação e luminosidade) e o seu impacto na reintegração cromática. Primeiramente é fundamental refletir sobre a natureza da própria lacuna, e desta forma caracterizar as problemáticas que coloca, analisar as propostas pré-existentes e definir os contornos de metodologia através da experimentação prática. Neste ensaio académico, utilizaram-se ferramentas informáticas de tratamento de imagem, com o objetivo de experimentar e aferir qual (ou quais) as variáveis mais relevantes para a reintegração cromática, dando-se especial atenção à luminosidade como um fator relevante na reintegração cromática, podendo ser utilizada como ferramenta de avaliação de uma reintegração.
\end{abstract}

Palavras-chave: reintegração cromática, lacuna, tonalidade, luminosidade, saturação, forma, textura

\section{Las tres dimensiones del color en la reintegración cromática diferenciada: la relevancia de la luminosidad.}

Resumen La reintegración cromática diferenciada tiene como objetivo reducir la percepción de la laguna como figura, y desde este principio se pretende, mediante los fenómenos de percepción, examinar las tres dimensiones del color (tonalidad, saturación y luminosidad) y su impacto en la reintegración cromática. En primer lugar es importante reflexionar sobre la naturaleza de la laguna, y asimismo caracterizar las problemáticas inherentes, analizar los métodos ya existentes y definir los principios de la metodología a través de la experimentación práctica. En este ensayo académico, se han utilizado herramientas informáticas de corrección de imagen, con el objetivo de experimentar y verificar cual (o cuales) son las variables más importantes para la reintegración cromática, se dando especial atención a la luminosidad como un factor de relevancia en la reintegración cromática, pudiendo ser utilizada como herramienta de evaluación de una reintegración..

Palabras clave: reintegración cromática, laguna, tonalidad, luminosidad, saturación, forma, textura

\section{The three dimensions of color on identifiable retouching: the importance of brightness}

Abstract: Identifiable retouching aims to reduce the perception of the lacunae as figure, and on this founding principle we intend, through the phenomena of perception, to examine the three dimensions of color (hue, saturation and brightness) and their impact on retouching. First it is important to consider the lacunae's nature for itself, and thus characterize the problems that take place, analyze the existing proposals and define the methodology contours through practical experimentation. In this academic study we used image edition software in order to experiment and verify which are the most relevant variables for retouching, giving special attention to brightness as a relevant factor on retouching and that can be used to evaluate retouching.

Keywords: retouching, lacunae, hue, brightness, saturation, shape, texture 


\section{Introdução}

\section{A problemática das lacunas e a necessidade de intervir}

Designamos por lacunas as ausências de matéria de uma obra de arte que poderão ser próprias da obra ou ocasionadas pela passagem do tempo sobre elas. Umberto Baldini denomina as primeiras de "lacunas-falta", já que surgem do facto de a obra de arte se encontrar incompleta/inacabada, e as segundas de "lacunas-perdida" pois devem-se a danos físicos ou químicos causados na matéria existente da obra de arte que não poderá ser reposta (Bailão 2010: 57).

Intuitivamente percebemos que a lacuna se apresenta como uma interrupção no "tecido" cromático de uma pintura que poderá quebrar a sua correta leitura, já que ganha um forte protagonismo visual em relação à pintura devido à sua interpretação como figura pelo observador.

Assim, Cesare Brandi adverte para a unidade da obra de arte, vista como um inteiro e não como um total (uma soma de diversas partes) e define dois corolários que levam à justificação de uma intervenção de reintegração:

A) “(...) a obra de arte, não sendo constituída de partes, ainda que fisicamente fragmentada, deverá continuar a subsistir potencialmente como um todo em cada um dos seus fragmentos e esta potencialidade será exigível numa proposição diretamente ligada à traça formal remanescente, em cada fragmento, à desagregação da matéria." (Brandi 2006:16).

B) "(...) se a 'forma' de cada obra de arte singular é indivisível, se por acaso a obra de arte estiver materialmente dividida, dever-se-á procurar desenvolver a potencial unidade original que cada um dos fragmentos contém, proporcionalmente à permanência formal ainda neles remanescente." (Brandi 2006:16).

Deste modo, a opção por uma intervenção de reintegração cromática tem por objetivo devolver à pintura a sua potencialidade estética e expressiva, opondo-se à nãointervenção que pretende dar preferência ao seu aspeto histórico. No entanto, a reintegração cromática, não ignorando o aspeto histórico das lacunas, no sentido que representam a passagem do tempo sobre a peça, deve ser realizada de forma diferenciada tanto ao nível dos materiais como da técnica para que não se corra o risco de realizar um falso histórico e artístico (Brandi 2006:16).

\section{Figura-fundo}

A lacuna apresenta-se como figura sobre a pintura que se torna fundo, sobressaindo ao olhar do observador, tendo Brandi recorrido à psicologia da Gestalt (ou gestaltismo) para explicar o porquê e procurar uma solução que contrariasse este fenómeno (Brandi 2006: 89; Bailão 2009: 131). Edgar Rubin enumera alguns princípios do fenómeno de perceção da forma como figura-fundo (Arnheim 1997: 227-232) importantes para a problemática das lacunas. Assim, as lacunas assumem frequentemente formas de grande simplicidade, regularidade e ainda próximas da simetria, sendo por isso facilmente distinguidas pelo observador (Bailão, 2009: 135). Apresentam, também, muitas vezes a sua camada de preparação (frequentemente de tonalidade clara) descoberta, ficando assim bastante evidentes e tornando-se ainda mais salientes quando estão presentes em superfícies de tonalidade escura.

Tal modo de percecionar prende-se ainda com os princípios de diferenciação que envolvem a justaposição de contrastes, ou seja, a diferença apenas é notória se existir a confrontação de características diferentes, por exemplo, um círculo destacase como círculo apenas quando estão disponíveis triângulos como alternativa (Arnheim 1997: 181). Deste modo, uma lacuna surge bem destacada da pintura pois trata-se de uma área de geometria relativamente simples, de cor e tonalidade uniforme e homogénea, apresentando geralmente uma maior luminosidade (devido à camada de preparação branca), que se opõe à superfície cromática.

\section{Metodologias pré-existentes}

Existem as mais diversas posições que podemos tomar perante uma lacuna: desde a não intervenção até à reintegração mimética. Estas duas atitudes opostas dão valor apenas à instância histórica ou à instância estética da pintura, respetivamente, ignorando a dupla polaridade das obras de arte (Brandi 2006). Não intervindo podemos correr o risco de tornar uma pintura num objeto arqueológico, podendose em casos extremos perder a leitura da obra; realizando uma reintegração mimética arriscamos a criação de um falso histórico. Deste modo consideramos que deve privilegiarse uma solução que respeite ambas as instâncias da obra de arte, sendo que, no entanto, não devemos esquecer que cada caso é um caso e que por vezes surge a necessidade de estabelecer metodologias particulares ${ }^{1}$.

Seguindo a teoria brandiana "deve-se reduzir o valor saliente de figura que a lacuna assume em relação à figura efetiva, que é a obra de arte" (Brandi 2006: 89), de forma diferenciada e restabelecendo a unidade da obra de arte. Em consenso, Ornella Casazza, baseada na teoria de Umberto Baldini, defende que "uma intervenção que pretenda fechar formalmente e cromaticamente uma lacuna ocorrida variavelmente e variavelmente apresentada no tecido cromático de uma obra de arte para não ser uma imitação, competição ou falsificação, nem que confronte o original existente deve ser diferenciada desta" (Casazza 1999: 9)².

Assim, existem diversas técnicas de reintegração diferenciada que apresentam vantagens e desvantagens que se adequam melhor ou pior a cada caso, mas que não deixam de se basear nos mesmos princípios essenciais: diminuição do impacto visual da lacuna como figura, reconhecimento facilitado da reintegração e restabelecimento da unidade da obra de arte (Brandi 2006: 90). 


\section{As três dimensões da cor (tom, saturação e luminosidade)}

Antes de aprofundarmos o tema, é de grande importância compreender as três dimensões da cor que o olho consegue distinguir: o tom/tonalidade/matiz, a saturação e a luminosidade. Tom ou matiz (hue) é a dimensão da cor que nos permite diferenciar um vermelho de um verde ou de um azul e classificar um amarelo em amarelo esverdeado ou amarelo alaranjado. A saturação (saturation ou croma) ${ }^{3}$ é o julgamento da quantidade de cor (Brommelle 1955: 76), ou seja, o afastamento ou aproximação de uma cor do cinzento com a mesma intensidade luminosa (Lopes 2013: 2). Por luminosidade (brightness ou lightness) entendemos a intensidade da luz refletida pela superfície, podendo-se distinguir entre claro - aproximação de uma cor ao branco e escuro - aproximação de uma cor ao preto.

Através destas três variáveis podemos caracterizar uma cor e diferenciá-la de outras, bastando uma pequena alteração numa das variáveis para estarmos perante uma cor diferente. No entanto, a classificação de uma cor mediante estas três dimensões mostra-se altamente subjetiva (Brommelle 1955: 76; Lopes 2013: 2) pois depende da comparação com outra cor, do julgamento de cada observador e da sua capacidade visual, isto é, da sua sensibilidade às cores (que varia de sujeito para sujeito). A perceção de uma cor depende ainda do tamanho da amostra de cor, da luz incidente (Lopes 2013: 2), assim como das cores que eventualmente a poderão circundar e que interagem entre elas ${ }^{4}$.

Vários modelos existem para sintetizar esta ideia onde são representadas as variações de saturação e luminosidade das mais diversas gradações de tonalidade 5 . No entanto, devemos salientar uma diferença muito relevante entre os modelos de cor-luz e de cor-pigmento. No primeiro caso, estamos perante as cores da luz, ou seja, as cores emitidas por fontes de luz (sol, lâmpadas, monitores de computador, etc.); no segundo, perante cores refletidas pelos materiais. Ora, o nosso olho perceciona de modo diferente estas duas realidades, não sendo possível fazer uma comparação direta entre uma cor vista num ecrã de computador e uma cor numa folha de papel ${ }^{6}$, o que se apresenta, desde logo, como limitação da nossa experimentação prática.

\section{Proposta metodológica experimental}

Como descrito na obra de Arnheim, "As relações entre tonalidades não podem ser corretamente descritas sem referência à saturação e luminosidade. Experiências têm mostrado que a distinção das cores depende mais da luminosidade do que da tonalidade. Liebmann descobriu que quando, por exemplo, uma figura vermelha é colocada num fundo verde de igual luminosidade, as suas fronteiras tornam-se fluídas, suaves, coloidais. A distinção figura-fundo desaparece, os objetos tornam-se incorpóreos, e diferenças de profundidade são difíceis de distinguir; a forma tende a desvanecer, as pontas das estrelas desaparecem, os triângulos parecem redondos, linhas formadas por pontos fundem-se. Deste modo, não é surpreendente que os pintores geralmente reforcem diferentes tonalidades através de diferentes luminosidades." (Arnheim 1997: 364) ${ }^{7}$. A partir deste conteúdo ideológico desenvolvemos a nossa proposta de estudo: qual a importância da luminosidade na reintegração cromática de uma lacuna? Na reintegração cromática diferenciada pretende-se que a lacuna deixe de ser percecionada como figura, remetendo-a para o mesmo plano que o tecido cromático, sem que, no entanto, deixe de estar presente. Ora, caminhando ao encontro das afirmações mencionadas supra, poderíamos reintegrar com qualquer cor desde que fosse mantida a luminosidade pois assim desapareceria a perceção de figura-fundo - "a distinção figura-fundo desaparece". Assim, neste ensaio académico pretende-se explorar a real importância da luminosidade para a reintegração cromática diferenciada, explorando a sua aplicação e os seus limites e ponderando sobre a possibilidade de reintegrar com uma cor de tonalidade diferente, até contrastante, ou ainda a preto e branco, desde que fossem mantidas as diferentes luminosidades da zona a reintegrar.

Ainda antes de entrarmos na experimentação e avaliação prática do efeito da luminosidade, analisamos a intervenção sobre o "Tríptico da Encarnação", pintura a óleo sobre madeira do século XVI e de origem flamenga [Figura 1]. Esta pintura apresenta uma reintegração (ou melhor, uma "reconstituição "(...) talvez discutível (...)" das áreas desaparecidas") (Bailão [et. al.] 2010: 134) na zona inferior dos dois volantes, realizada em duas cores: uma base ocre/terra e o contorno da figuração a sépia. Como afirmou Fernando Mardel (autor desta reintegração) "prolongou-se o contorno do desenho num tom sépia de cor neutra para apenas obter um conjunto mais agradável ao quadro" (Bailão [et. al.] 2010: 134). O modo como as lacunas foram reintegradas despertou-nos interesse

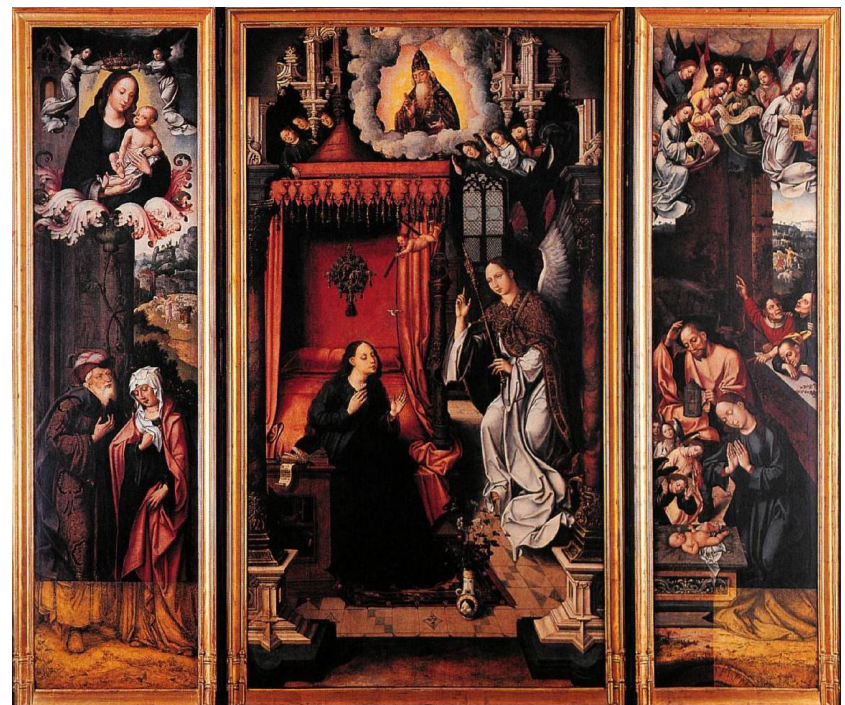

Figura 1.- Tríptico da Encarnação. Fonte: BAILÃO, A. [et. al.] «Primeiros passos de maturidade a caminho da reintegração cromática diferenciada em pintura de cavalete em Portugal». In Ge-conservation, n¹, 2010, p. 129 


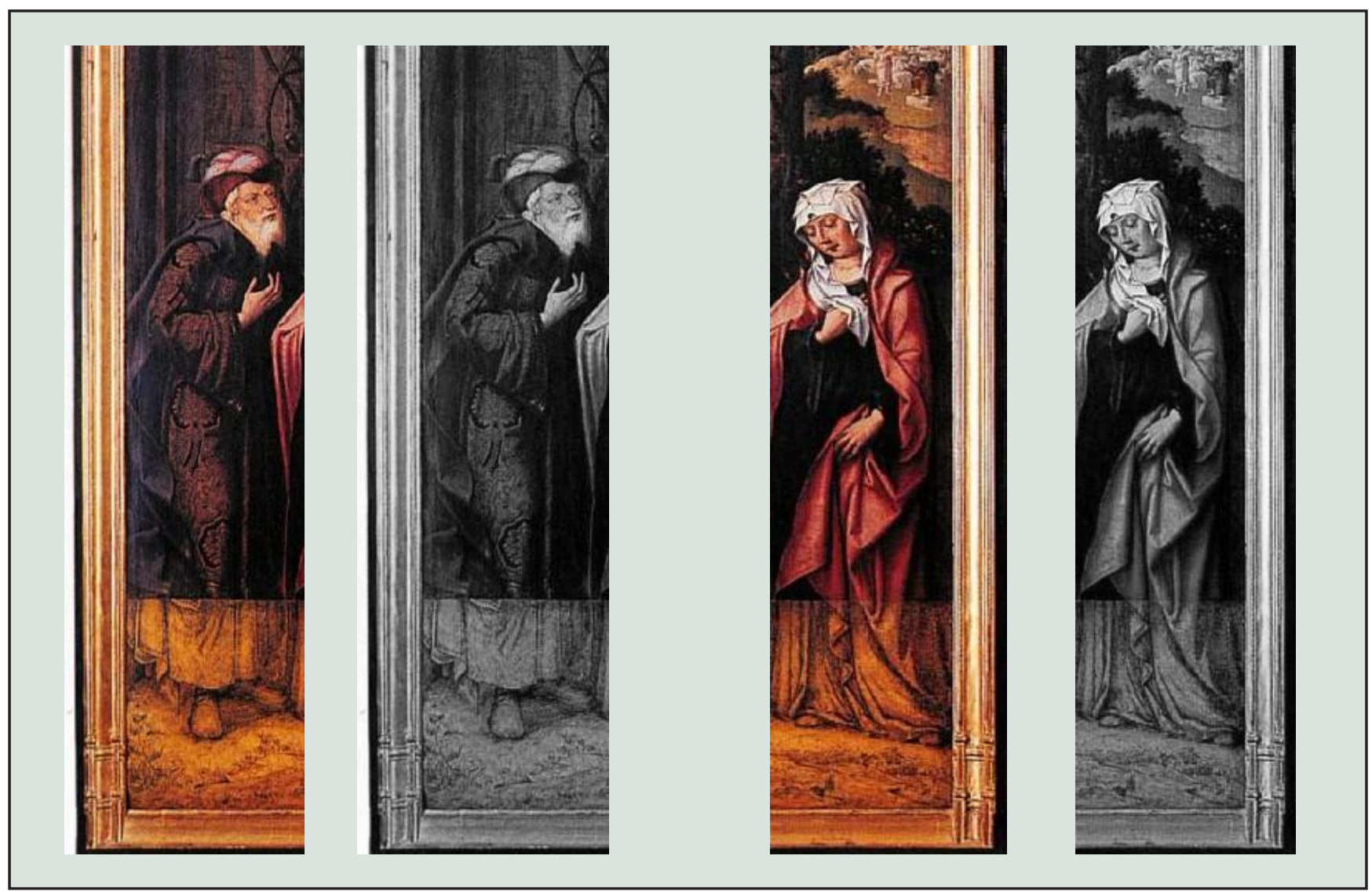

Figura 2.- Pormenor da reintegração (manto escuro e manto claro) - imagem com e sem saturação

pois, não se aproximando das cores da pintura, apresentava certas zonas que se harmonizavam com a pintura original não se destacando violentamente perante o olhar do observador.

Procedemos, então, à análise da reintegração do volante esquerdo - Genealogia da Virgem ${ }^{8}$. Por observação, constatamos que o lado direito da zona reintegrada, ou seja, o prolongamento do manto claro (da Virgem), se destacava menos do que o lado esquerdo correspondente ao prolongamento de um manto escuro. No sentido de tentar esclarecer este fenómeno de perceção, realizamos a dessaturação das imagens, de modo a obter apenas diferenças de luminosidade, podendo-se concluir que - lado da área reintegrada que menos se destacava apresentava uma luminosidade semelhante à da pintura original enquanto no lado esquerdo o contraste luminoso era acentuado [Figura 2].

\section{Experimentação Prática}

Selecionamos a fotografia de uma pintura: a cópia de um pormenor do retrato de Juan de Pareja de Velázquez. Nesta imagem foi provocada, virtualmente, uma lacuna de grande dimensão, abrangendo uma zona vital da composição [Figura 3].

Os ensaios foram impressos em papel normal e realizamos a reintegração das lacunas com aguarela através da
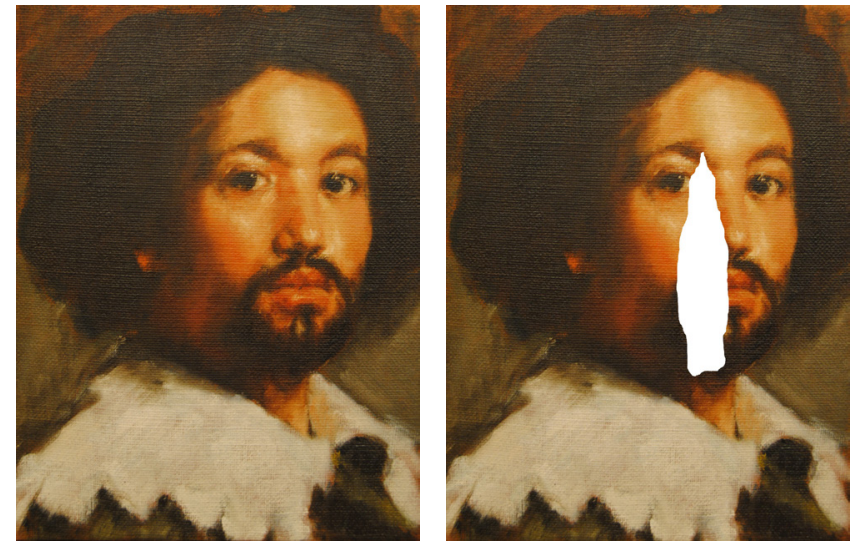

Figura 3.- Simulação de lacuna em cópia de pormenor do Retrato de Juan de Pareja de Velázquez
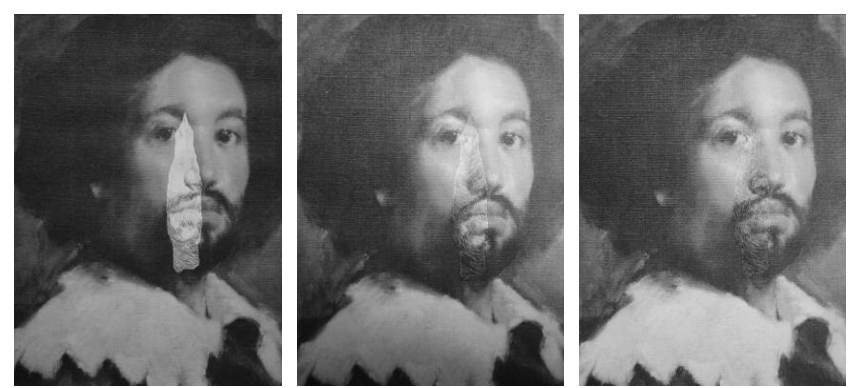

Figura 4.- Controlo do grau de luminosidade durante a reintegração cromática 
técnica de seleção cromática para que a construção da reintegração fosse progressiva e controlada até se obter a luminosidade desejada.

Para o controlo do grau de luminosidade da reintegração comparativamente à envolvente da lacuna, foram sucessivamente tiradas fotografias a preto e branco, para que apenas se pudesse observar a luminosidade sem influência da tonalidade, até se obter o grau pretendido [Figura 4].

A) No primeiro exercício, a escolha do tom para a reintegração teve como critério a complementaridade com os tons principais da pintura, tendo sido escolhido o azul por oposição aos tons alaranjados da carnação.

B) No segundo exercício, optamos pela exclusão da saturação e tonalidade, ou seja, a reintegração foi feita a preto e branco.

C) Numa terceira fase, estudamos a influência da forma, da textura e da saturação nos resultados obtidos. As lacunas reintegradas foram simuladas por via digital.

É de extrema importância salientar que para a realização deste último exercício trabalhamos num ecrã de computador, utilizamos um modelo de cor RGB de corluz e não cor-pigmento, existindo diferenças na perceção visual dos dois sistemas. Logo, as conclusões que daqui advenham necessitam de uma posterior experimentação prática.

\section{Análise de resultados}

A) Oresultado obtido foinegativo pois a corapresentou uma forte saliência apesar de a luminosidade ser a mesma. A lacuna continuou a apresentar uma forte presença como figura, continuando a quebrar acentuadamente a leitura da obra [Figura 5].

Este resultado negativo deve-se à má escolha da cor explicado por dois fatores relacionados com a harmonia das cores:

O efeito de desvanecimento dos limites da figura não é possível com duas tonalidades contrastantes (como o azul e o laranja), sendo necessária a utilização de tonalidades mais próximas (Albers 2006: 62).

Segundo Ruhemann, o desvio de uma reintegração é mais notória se a cor utilizada estiver fora da gama de cores da pintura como um todo. "Assim, um desvio do azul-verde, numa pintura com uma gama de tonalidades azul-verde, amarelo, laranja-vermelho pode ser aceitável, mesmo quando a mudança de tonalidade é grande, desde que vá de encontro ao
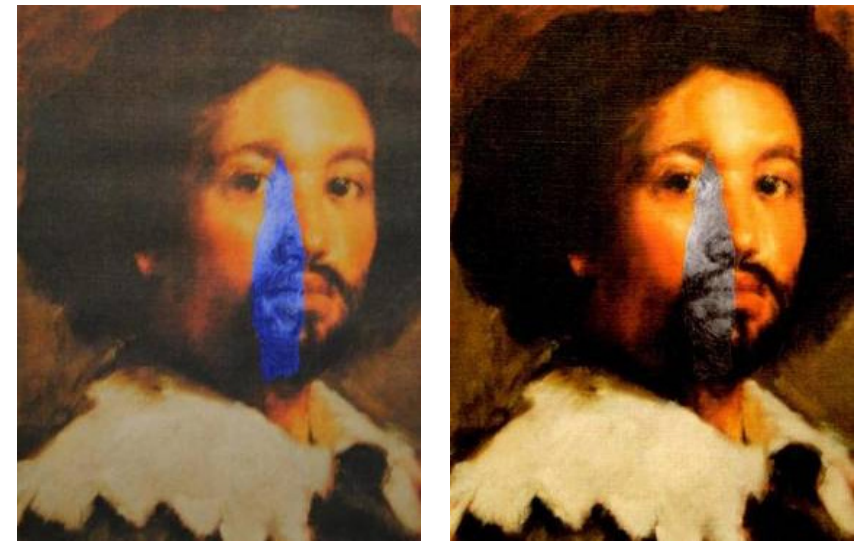

Figura 5 y 6.- Figura 5: Reintegração cromática em tons de azul (A). Figura 6: Reintegração cromática em tons de cinza (B)

verde ou amarelo e não de encontro ao azul ou roxo" (Brommelle 1955: 83) .

B) Este exercício apresentou como resultado uma ligeira diminuição da presença da lacuna, mas levounos a questionar diversos problemas na reintegração cromática, nomeadamente a textura, a saturação e a forma da própria lacuna. Constatámos que uma série de fatores estavam em jogo para realçar o valor da lacuna. Lidávamos com uma série de variáveis, já referidas, mas ainda com a subjetividade da visão humana que difere de pessoa para pessoa, que tornavam difícil a definição de conclusões. Por este motivo se mostrou necessária a realização da terceira etapa deste estudo [Figura 6].

Podemos neste exercício observar que a saliência da zona reintegrada prende-se também com o facto de o cinzento não ser um tom próximo do amarelo/ laranja (como vimos no primeiro exercício). De facto, os contornos da lacuna desvanecem-se nas zonas de sombra da carnação, na barba e cabelo pois a sua tonalidade aproxima-se do preto.

C) Nesta terceira etapa, optámos por estudar as variáveis referidas anteriormente eliminando a perturbação causada pela textura. Para tal, foram realizadas alterações digitais, definindo-se áreas de corte (regulares e irregulares), que corresponderiam às lacunas reintegradas, onde foi alterada a saturação, a tonalidade e a luminosidade. [Figura 7 e 8].

Pela conjugação dos exercícios B e C, podemos retirar algumas considerações das observações feitas, que apresentamos e analisamos infra.

\section{Forma da lacuna}

Como vimos anteriormente, a nossa perceção visual destaca mais facilmente como figura as formas 


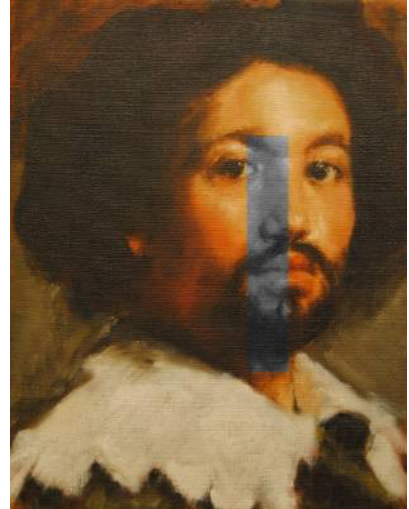

a) - $100 \%$ de saturação

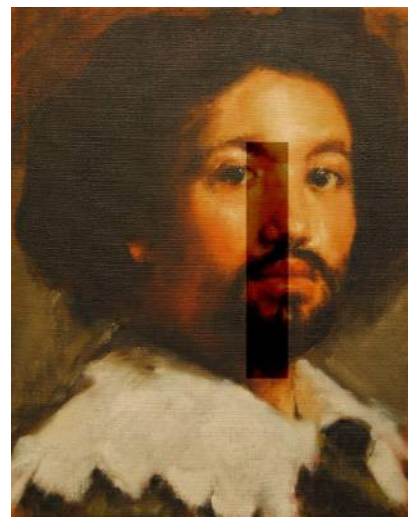

d) - $30 \%$ de luminosidade

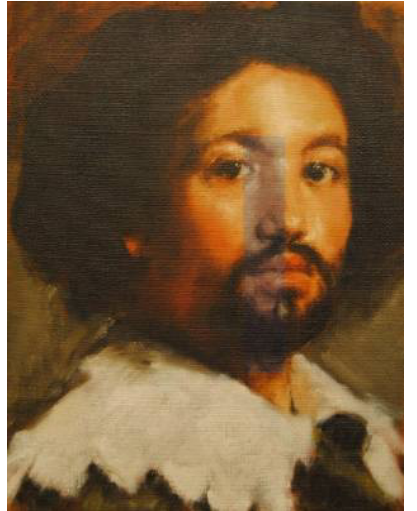

b) - $50 \%$ de saturação

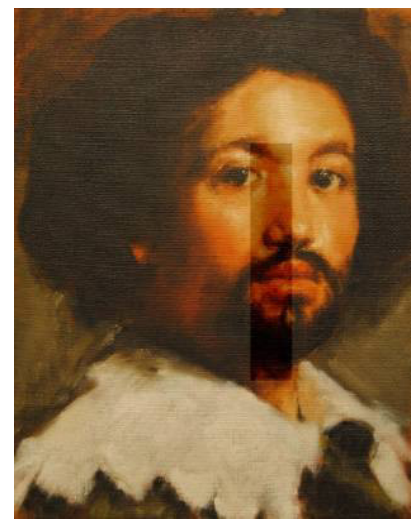

e) - $15 \%$ de luminosidade

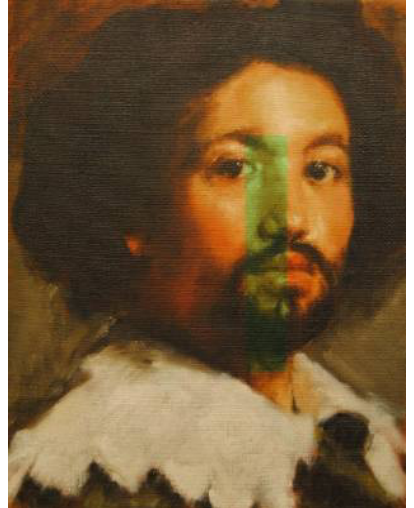

c) $30 \%$ de tom verde

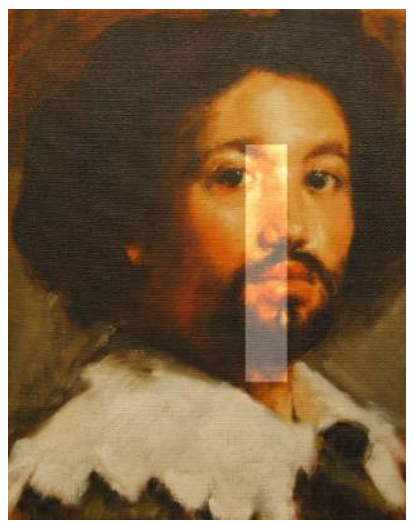

f) $+30 \%$ de luminosidade

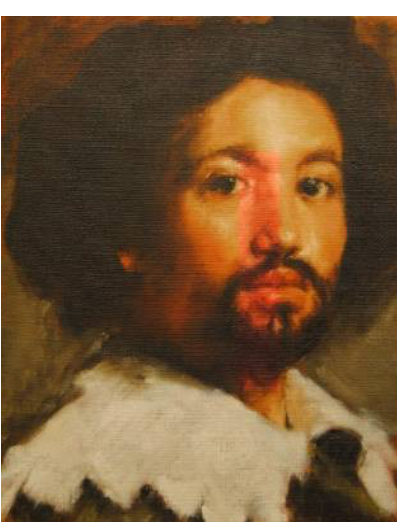

c) $30 \%$ de tom vermelho

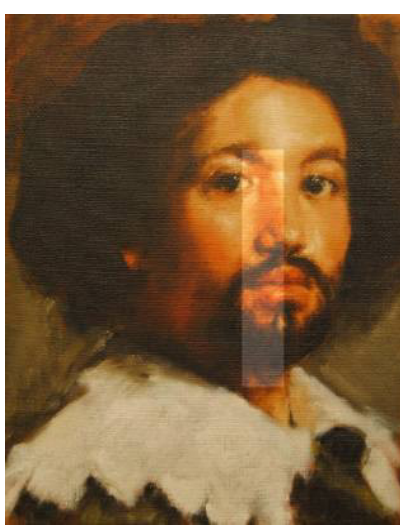

g) $+15 \%$ de luminosidade

Figura 7.- Simulação por computador da reintegração cromática de lacunas regulares (C)

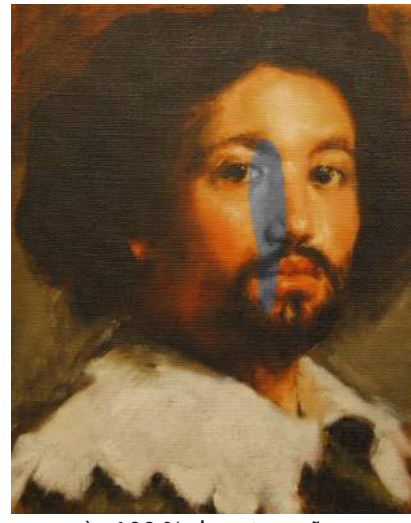

a) - $100 \%$ de saturação

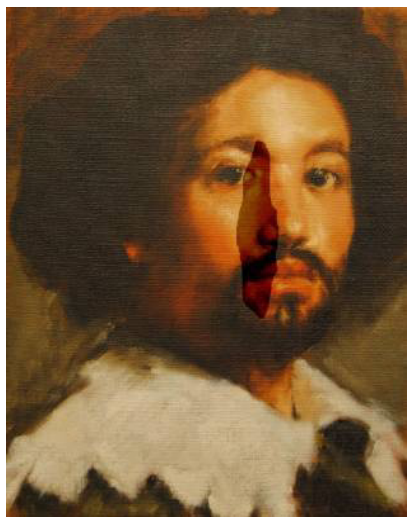

e) - $30 \%$ de luminosidade

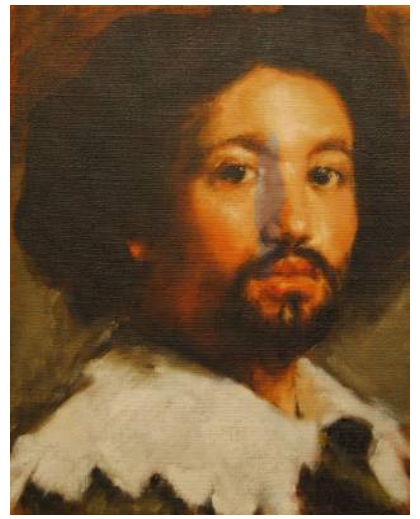

b) - $50 \%$ de saturação

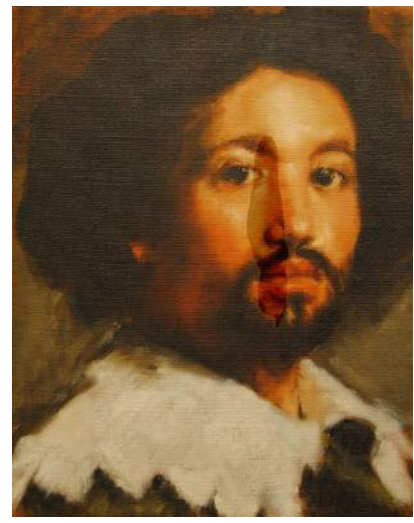

f) - $15 \%$ de luminosidade

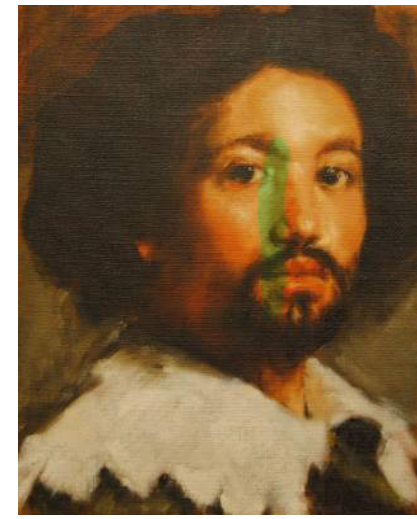

c) $30 \%$ de tom verde

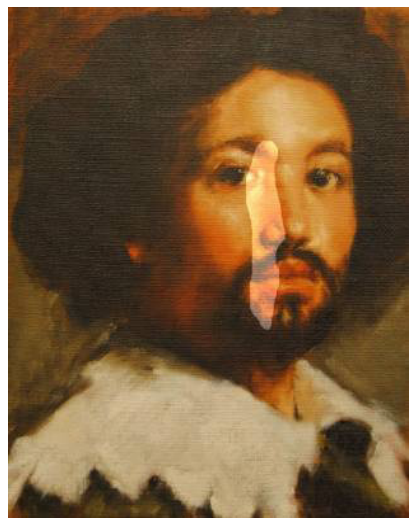

g) $+30 \%$ de luminosidade

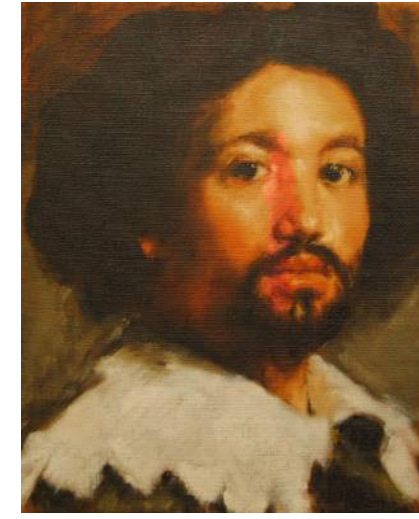

c) $30 \%$ de tom vermelho

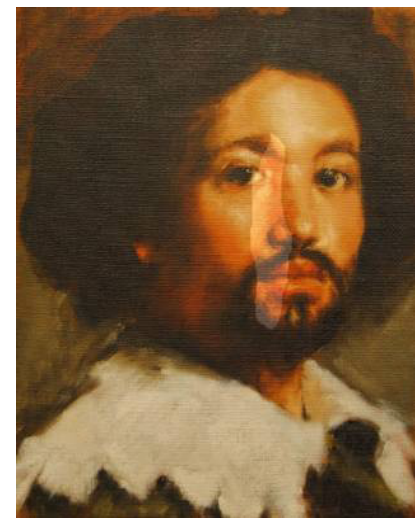

h) $+15 \%$ de luminosidade

Figura 8.- Simulação por computador da reintegração cromática de lacunas irregulares (C) 
simples, regulares e simétricas, acrescentando-se a este fator os princípios de diferenciação (confrontação de características diferentes). Assim, comparando os exercícios que apresentam lacunas regulares, em forma de retângulo [Figura 7], com os que apresentam lacunas de forma mais irregular [Figura 8], imediatamente observamos que as primeiras são mais rapidamente percecionadas, independentemente do modo como foram reintegradas. De facto, toda a pintura apresenta contornos orgânicos, sem que existam linhas retas, levando a que os limites irregulares de uma lacuna se integrem melhor na composição em oposição a limites rígidos.

Do mesmo modo, podemos observar as lacunas reintegradas do Tríptico da Encarnação que apresentam limites muito retos e geométricos, levando a um certo destaque das reintegrações.

\section{Textura}

Comparando o exercício realizado em B [Figura 6] com o exercício equivalente da etapa $C$ [Figura 8a], poderemos questionar sobre o papel da textura. Na figura 6, para além da diferenciação de tonalidade e saturação, presentes na figura 8a, deparamo-nos também com uma diferença de textura, que evidencia a presença da lacuna como figura pois torna a área mais densa e pesada. Ainda reforçando o papel da textura, Brommelle afirma que o olho pode ser facilmente iludido no que respeita a tonalidade, contudo mantém-se sensível a variações de luminosidade e textura (Brommelle 1955: 84).

\section{Saturação, Tonalidade e Luminosidade}

Mostrou-se difícil analisar o efeito causado por estas três dimensões da cor em separado visto estarem intimamente ligadas e influenciarem-se mutuamente.

Na tabela que se segue, sistematizamos as alterações realizadas na zona de lacuna em relação ao original e os resultados obtidos, através de observação, da sua reintegração no plano da pintura, classificados em três categorias: bom, razoável e mau (consideramos apenas as lacunas regulares visto terem áreas, formato e localização iguais).

Da observação destas figuras e da tabela, concluímos que a solução de reintegração da lacuna que menos se destaca é a da Figura 7d que mantém a mesma luminosidade e saturação da pintura original, existindo apenas um desvio de tonalidade em direção ao vermelho.

Constatamos também que o pior resultado, isto é aquele em que a reintegração não exerce grande efeito na interpretação percetual da lacuna como figura, coincide com a Figura 7a onde foram alteradas duas variáveis: a saturação e a tonalidade. Aos resultados negativos acrescentamos as Figuras 7 e e $7 \mathrm{~g}$ que correspondem a variações de luminosidade acentuadas e a Figura 7c onde foi desviada a tonalidade para um verde.

Dos resultados razoáveis, ou seja, aqueles em que a presença da lacuna éatenuada masfacilmente reconhecível destacamos as figuras em que a luminosidade da zona reintegrada se aproxima da pintura original [Figuras $7 f$ e 7h]. e em que a saturação foi alterada, mas que não se afasta muito do original [Figuras 7b].

\section{Discussão de resultados}

Observando estes resultados, podemos afirmar que a reintegração diferenciada de uma lacuna é um problema de extrema complexidade que joga com diversos fatores variáveis. Antes de mais, lida com a perceção visual do ser humano que, como sabemos, varia de indivíduo para indivíduo, sendo por isso subjetiva. Contudo, é possível estabelecer normas de perceção, salientando-se para esta problemática do restauro os princípios da figura-fundo e da diferenciação. Acrescenta-se ainda a localização e forma da lacuna que não podem ser controladas pelo conservador-

Tabla 1.- Resultados da perceção de lacunas em função das alterações efetuadas

\begin{tabular}{ccccc}
\hline Figura & Saturação & Tonalidade & Luminosidade & Resultado \\
\hline $7 a$ & $-100 \%$ & Cinza & --- & Mau \\
\hline $7 b$ & $-50 \%$ & --- & -- & Razoável \\
\hline $7 c$ & --- & Verde $(30 \%)$ & -- & Mau \\
\hline $7 d$ & --- & Vermelho $(30 \%)$ & -- & Bom \\
\hline $7 e$ & --- & -- & $-30 \%$ & Mau \\
\hline $7 f$ & --- & --- & $+30 \%$ & Mazoável \\
\hline $7 g$ & --- & --- & $+15 \%$ & Razoável \\
\hline $7 h$ & --- & --- & &
\end{tabular}


restaurador. Contudo, pode mostrar-se útil para a decisão da solução a tomar o conhecimento da influência da forma na perceção da lacuna. Sendo impossível de controlar estas variáveis, podemos estabelecer outras quatro - textura, luminosidade, saturação e tonalidade - que poderão mais facilmente ser controladas pelo conservador-restaurador.

Na decisão da solução de reintegração cromática a escolher é útil perceber que quanto mais variáveis se afastarem do original mais rapidamente será percecionada a lacuna pelo observador. Deste modo, uma reintegração mimética (impercetível) não alteraria nenhuma das variáveis que mencionamos; as soluções diferenciadas propostas pelo pontilhismo, trattegio, seleção cromática e abstração cromática fazem variar essencialmente a textura; o sub-tom faz variar a luminosidade da reintegração e eventualmente a tonalidade e textura sendo, por isso, mais percetível do que as técnicas anteriores; o tom neutro poderá alterar as três variáveis da cor (luminosidade, saturação e tonalidade) e a textura tornando-se a mais distintiva das técnicas de reintegração diferenciada.

Os testes aqui apresentados levam-nos a caminhar em direção a algumas possíveis conclusões que vão de encontro a fenómenos explicados por autores como Liebmann, Albers, Ruhemann ou Brommelle.

-A luminosidade revela-se um importante fator de diferenciação de uma zona reintegrada que não deve ser ignorado.

-Quanto mais próximas as três dimensões da cor estiverem do original, mais fundida ficará a lacuna com a composição da pintura.

- A escolha da tonalidade para a reintegração cromática poderá ter uma variação maior/um leque de escolha mais abrangente do que a luminosidade.

No entanto,

-Para que tal fenómeno ocorra é necessário que a tonalidade escolhida não seja muito contrastante com os tons envolventes e que se enquadre preferencialmente na gama de tonalidades presentes na pintura.

Estas conclusões sobre o papel da luminosidade na reintegração cromática levam-nos a questionar ainda sobre o efeito do metamerismo. Explicado de forma sucinta, o metamerismo é um fenómeno próprio das superfícies cromáticas que provoca a alteração da cor percecionada dependendo da luz incidente na superfície. Este fenómeno é particularmente indesejado quando se pretende uma reintegração mimética, já que, quando utilizados pigmentos diferentes 10, uma reintegração que seja invisível à luz do dia pode-se tornar visível quando a pintura é observada em condições de luz diferentes ou quando é fotografada (Staniforth 1985: 101). Assim, quando não é pretendida uma reintegração mimética, o conservador restaurador terá uma maior liberdade e despreocupação perante este fenómeno pois uma variação de tonalidade poderá não ser problemática quando o grau de luminosidade se encontra bem aplicado na reintegração cromática da lacuna.

\section{Conclusão}

A reintegração cromática é uma das grandes problemáticas na Conservação e Restauro, alvo de grande discussão e controvérsia. Primeiro, por se tratar de uma questão deontológica, pois não se pretende criar falsos históricos ou estéticos. Colocam-se as questões: intervir ou não intervir? e de que modo? Esta segunda questão leva-nos ao tema deste artigo; podemos afirmar que existe um leque muito vasto de soluções que dependem de uma escolha subjetiva, principalmente quando se pretende fazer uma reintegração diferenciada.

No entanto, através da análise dos fenómenos da perceção visual (nomeadamente da teoria da Gestalt e da interação das cores) e do conhecimento das várias dimensões da cor, podemos começar a delinear diretrizes que orientem o modo de reintegrar diferencialmente. Deste estudo destacamos: os efeitos da textura e da forma da lacuna; a importância de uma correspondência correta de luminosidade entre a zona reintegrada e a obra; assim como da saturação e da tonalidade. Quando o grau de luminosidade da reintegração de lacuna é corretamente aplicado, os desvios de tonalidade da zona reintegrada tornam-se menos relevantes desde que esse desvio se aproxime da gama de tons da pintura, e efeitos de metamerismo poderão tornar-se irrelevantes. Assim, a reintegração cromática poderá estar aberta a um leque mais diverso de soluções do que as que, pela tradição italiana, são aplicadas em Portugal.

A luminosidade pode, ainda, constituir um meio de avaliação do grau de reintegração de uma lacuna, utilizando-se para tal a fotografia a preto e branco da zona de lacuna [Figura 4]. Deste modo, é possível verificar facilmente se a luminosidade da zona reintegrada se encontra próxima do original, sendo por isso uma ferramenta de grande ajuda para o conservadorrestaurador.

Por último, resta-nos referir que este artigo representa apenas um pequeno ensaio académico que deverá ser aprofundado e testado. Salienta-se o facto de ter sido realizado, em parte, por via digital, o que torna necessária uma aplicação prática para resultados mais precisos e corretos. Salienta-se ainda que os testes foram realizados num só protótipo, e deverão posteriormente ser realizados numa maior diversidade de exemplos com características distintas, nomeadamente em pintura contemporânea que utiliza, não raras vezes, superfícies monocromáticas de grande área. 


\section{Notas}

[1] A escolha pela técnica de reintegração não só depende da obra com que nos deparamos mas também depende do meio cultural de origem e onde está inserida atualmente, da sua simbologia, do local onde se encontra, do proprietário e do critério do conservador restaurador (Bailão 2011). Dificilmente poderemos afirmar que uma técnica está completamente errada.

[2] Tradução das autoras do original em italiano: “Um intervento atto a 'chiudere' formalmente e cromaticamente una 'perdita' variamente occorsa e variamente presentantesi nel tessuto epiteliare di un'opera di arte per non essere imitativo, competitivo o falsificante nei confronti com l'esistente originale deve essere anzitutto 'diferenziato' da questi."

[3]http://www.criarweb.com/artigos/teoria-da-corpropriedades-das-cores.html

[4] Se se pretender desenvolver e perceber a interação das cores entre elas, devemos salientar a seguinte monografia: ALBERS, J. - Interaction of color. Revised and expanded edition. Yale: Yale University Press, New Haven London, 2006

[5] A seguinte referência apresenta diversos modelos de cor: LOPES, J. - Cor e luz. Lisboa: Instituto Superior Técnico, 2013.

[6] Este factor é de extrema importância para a interpretação dos resultados deste exercício, pois uma etapa da experimentação prática foi realizada em meio digital, logo num sistema rgb.

[7] Tradução das autoras do original em inglês: "Relations between hues cannot be described adequately without reference to saturation and brightness. Experiments have shown that the distinctness of color depends more upon brightness than upon hue. Susanne Liebmann found that when, for example, a red figure is put on a green background of exactly equal brightness, the boundaries become fluid, soft, colloidal. The figure-ground distinction vanishes, objects look incorporeal, and differences of distance are hard to distinguish; shape tends to melt, the points of stars disappear, triangles look rounded, rows of dots merge. Therefore it is not surprising that painters usually reinforce differing hues by differing brightness. When they do entrust distinction between neighboring areas to hue alone, they rely mostly on what I have called clash or mutual repulsion. For example, there may be a blue-green background bardering on a reddish-blue coat of approximately identical brightness and saturation. This would seem to confirm the view that the most effective distinction between hues is brought about by clash."

[8]http://www.museuartesacrafunchal.org/arteflamenga/ flamenga_pintura_img0c.html

[9] Tradução das autoras do original em inglês: "One is the principle pointed out to the author by $\mathrm{H}$. Ruhemann that a given deviation from a match is most noticeable if the deviation is away from the colour gamut of the picture as a whole. Thus a deviation from blue-green, in a picture with a blue-green, yellow, orangered gamut may be acceptable, even when the hue change is large, as long as it is towards the green and yellow and not towards a mid blue or purple."

[10] Muitos dos pigmentos utilizados em pintura antiga já não são empregues nos nossos dias devido à sua toxicidade, tendo sido substituídos por outros pigmentos que poderão apresentar curvas de reflectância diferentes, logo poderão ter uma tonalidade diferente consoante a fonte de iluminação (metamerismo).

\section{Bibliografía}

ALBERS, J. - Interaction of color. Revised and expanded edition. Yale: Yale University Press, New Haven London, 2006.

ARNHEIM, R. - Art and visual perception. A psychology of the creative eye. London: University of California Press, Ltd., 1997.

CASAZZA, O. - II restauro pittorico nell'unità di metodologia. Firenze: Nardini Editore, 1999 (6ª edição).

BAILÃO, A. - O gestaltismo aplicado à reintegração cromática de pintura de cavalete. In Estudos de Conservação e Restauro. Porto: Universidade Católica Portuguesa, Centro de Investigação em Ciência e Tecnologia das Artes, 2009; pp. 128-139.

BAILÃO, A. - Metodologia e técnicas para a reintegração cromática em pintura de cavalete. Porto: Universidade Católica Portuguesa, 2010 [Tese de Mestrado].

BAILÃO, A. - As técnicas de reintegração cromática na pintura: revisão historiográfica. In Ge-conservación, n¹, 2011; pp. 28-46.

BAILÃO, A. [et. al.] - Primeiros passos de maturidade a caminho da reintegração cromática diferenciada em pintura de cavalete em Portugal. In Ge-conservation, n¹, 2010, pp. 127-139.

BRANDI, C. - Teoria do restauro. Amadora: Edições Orion, 2006.

BROMMELLE, N. "Colour and Conservation» In Studies in Conservation, vol. 2, n², 1955; pp. 76-86. [Consulta: 31/05/2013] http://www.jstor.org/stable/1504920

LOPES, J. «Cor e luz» Lisboa: Instituto Superior Técnico, 2013. [Consulta: 16/06/2013] http://disciplinas.ist.utl.pt/leic-cg/textos/ livro/Cor.pdf

STANIFORTH, S. «Retouching and colour matching: the restorer and metamerism» In Studies in Conservation, vol. 30, n० 3, 1985; pp. 101-111. [Consulta: 12/02/2011] http://www.jstor.org/ stable/1505925

[Consulta: 16/06/13] http://www.criarweb.com/artigos/teoriada-cor-propriedades-das-cores.html

[Consulta:17/06/13]http://www.museuartesacrafunchal.org/ arteflamenga/flamenga_pintura_img0c.html 


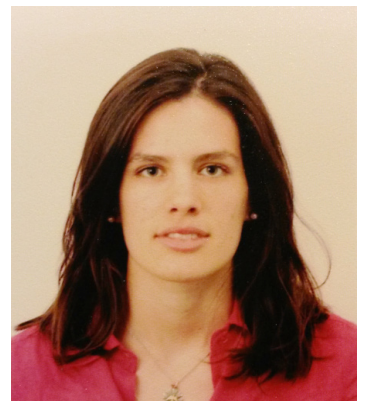

\section{Ana Braamcamp de Figueiredo}

ana.braamcamp.de.figueiredo@gmail.com

Mestre em Conservação e Restauro de Bens Culturais, especialização em Pintura, pela Universidade Católica Portuguesa desde 2016. Licenciada em Conservação e Restauro desde 2012, pela mesma Universidade.

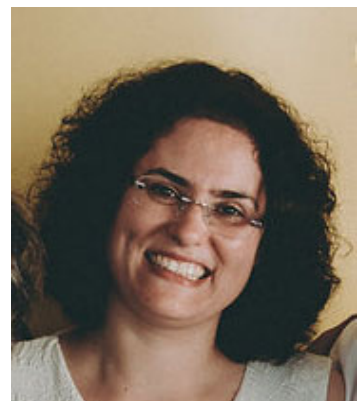

\section{Salomé de Carvalho}

salome.de.carvalho@gmail.com

Doutorada em Conservação e Restauro pela Escola das Artes da Universidade Católica Portuguesa - Centro Regional do Porto (2013), onde concluiu também licenciatura (2006). É docente convidada, investigadora integrada do CITAR, e membro do conselho de redação da Revista ECR - Estudos de Conservação e Restauro, na mesma instituição. Bolseira de investigação Laboratório José de Figueiredo / FCT / Museu Nacional de Soares dos Reis desde 2011.

Artículo enviado el 12/09/2015

Artículo aceptado el 14/04/2016 